\title{
A rash decision. The hazards of the wrongful use of adrenaline
}

\author{
Madalena Coutinho Cruz, Ramiro Sá Carvalho, Pedro Modas Daniel, Rui Cruz Ferreira
}

Cardiology Departament, Hospital de Santa Marta, Centro Hospitalar Lisboa Central, Lisbon, Portugal

\begin{abstract}
Anaphylaxis is life-threatening and should be addressed urgently. Its treatment is not without side effects and an accurate diagnosis must be made to prevent potential harm by the wrongful use of medication. A 46-year-old woman with hypertension treated with angiotensin converting enzyme inhibitor (ACEI) presented to the emergency department with non-pitting oedema of the face and limbs. A hasty diagnosis of anaphylaxis was made and intravenous adrenaline administered. The patient developed a myocardial infarction caused by coronary artery spasm that required invasive intervention. The initial clinical picture was resolved when the ACEI was discontinued unmasking a case of ACEI-induced angioedema. The correct differentiation of these two apparently similar clinical entities is of utmost importance in the management of emergency department patients.
\end{abstract}

Keywords: ACEI-induced angioedema, anaphylaxis, adrenaline, acute myocardial infarction

\section{Introduction}

Intramuscular adrenaline is the mainstay of treatment of anaphylaxis [1]. The clinical diagnosis of this entity can be challenging in the emergency setting and can lead to the unnecessary use of this medication, which may have dire consequences for the patients. On the other hand, angiotensin converting enzyme inhibitor (ACEI)-induced angioedema does not respond to this kind of therapy and resolves with the discontinuation of the causative drug [2]. The accurate differentiation of these two entities is the key to the optimal management of patients presenting to the emergency department.

Address for correspondence:

Madalena Coutinho Cruz, MD

Cardiology Departament,

Hospital de Santa Marta,

Centro Hospitalar Lisboa Central

Rua de Santa Marta, 1169-1024

Lisbon, Portugal

E-mail: madalena.cruz89@gmail.com

\section{Case report}

A 46-year-old woman with hypertension, obesity and smoking habits (20 pack-years), who was taking perindopril $10 \mathrm{mg}$ daily for about one year, presented to the emergency department with swelling in the face (mainly lips and eyelids), arms and hands, which had woken her up from sleep at 5:00 AM. She also complained of slight dyspnoea. Skin rash or pruritus were not present. No causative agent for an allergic reaction could be identified. At admission, non-pitting edema of the face and upper limbs was noted. The patient had stable vital signs and a normal cardiopulmonary auscultation. She was medicated with $200 \mathrm{mg}$ of hydrocortisone, $2 \mathrm{mg}$ of clemastine and $1 \mathrm{mg}$ of adrenaline intravenously. Shortly after, she developed oppressive chest pain and nausea, sinus tachycardia (150 beats per minute), hypotension (arterial pressure of 60/27 $\mathrm{mmHg}$ ), tachypnea (27 cycles per minute). An electrocardiogram (ECG) showed sinus rhythm and a $4 \mathrm{~mm}$ ST-segment elevation in leads DII, DIII, V5 and V6 with reciprocal ST-segment depression in leads V1, V2 and aVR (Figure 1). The echocardiogram revealed good left and right ventricular function and hypokinesis 


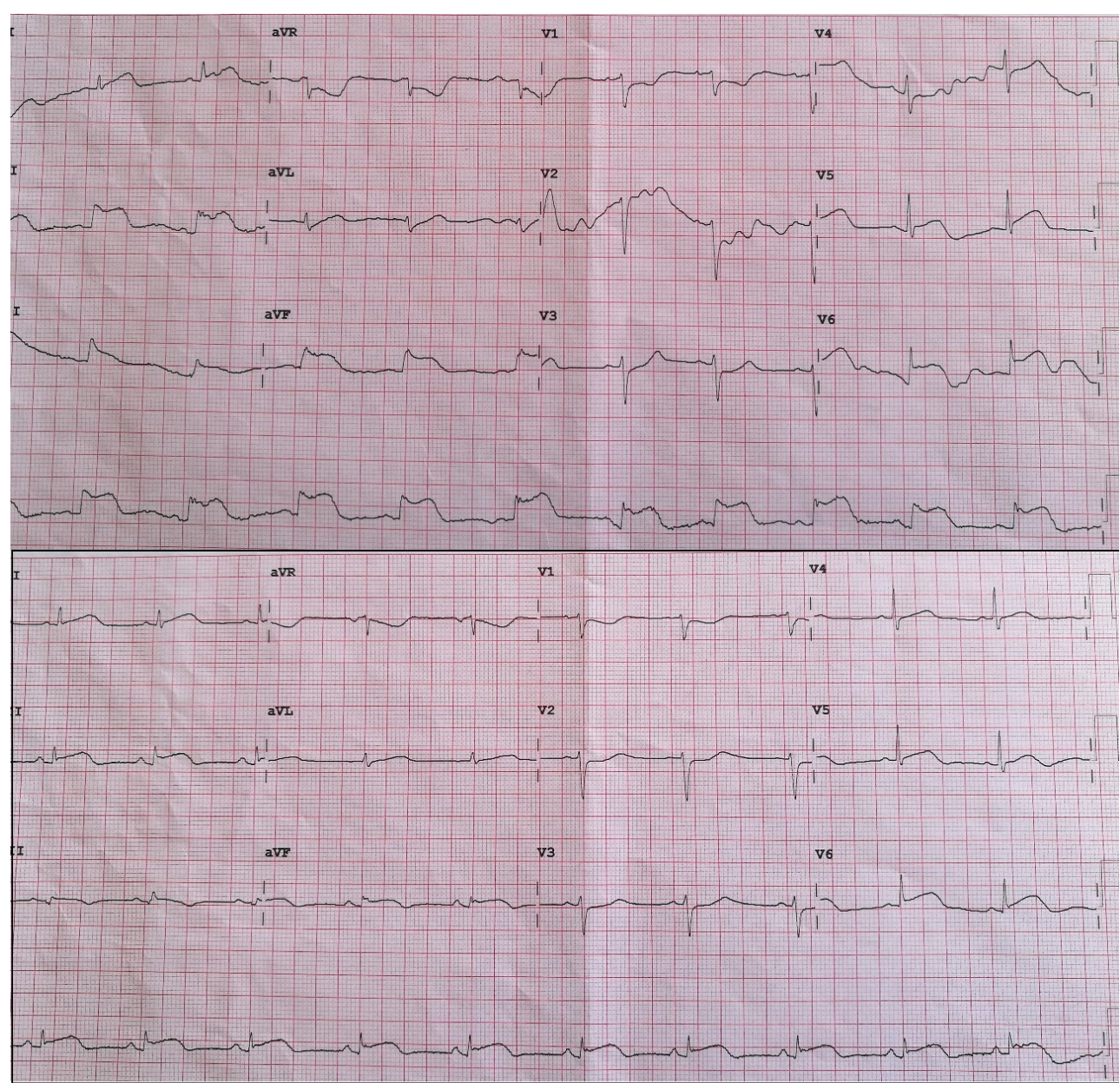

Fig. 1. First ECG showing $4 \mathrm{~mm}$ ST-segment elevation in leads DII, DIII, V5 and V6 with reciprocal ST-segment depression in leads V1, V2 and aVR (top), repeated after sublingual nitroglycerin with partial attenuation of the ST-segment elevation to $1.5 \mathrm{~mm}$ (bottom)

of the medio-basal inferior and lateral walls. $0.5 \mathrm{mg}$ of sublingual nytroglicerine was given and then repeated 5 minutes later with partial improvement in pain and attenuation of the ST-segment elevation to $1.5 \mathrm{~mm}$ (Figure 1).
She was transferred to our tertiary cardiology center and submitted to a coronary angiography, which displayed an intermediate lesion in the distal right coronary artery (Figure 2) that was quantified as a $78 \%$ stenosis by intravascular ultrasound (IVUS) and had no signs

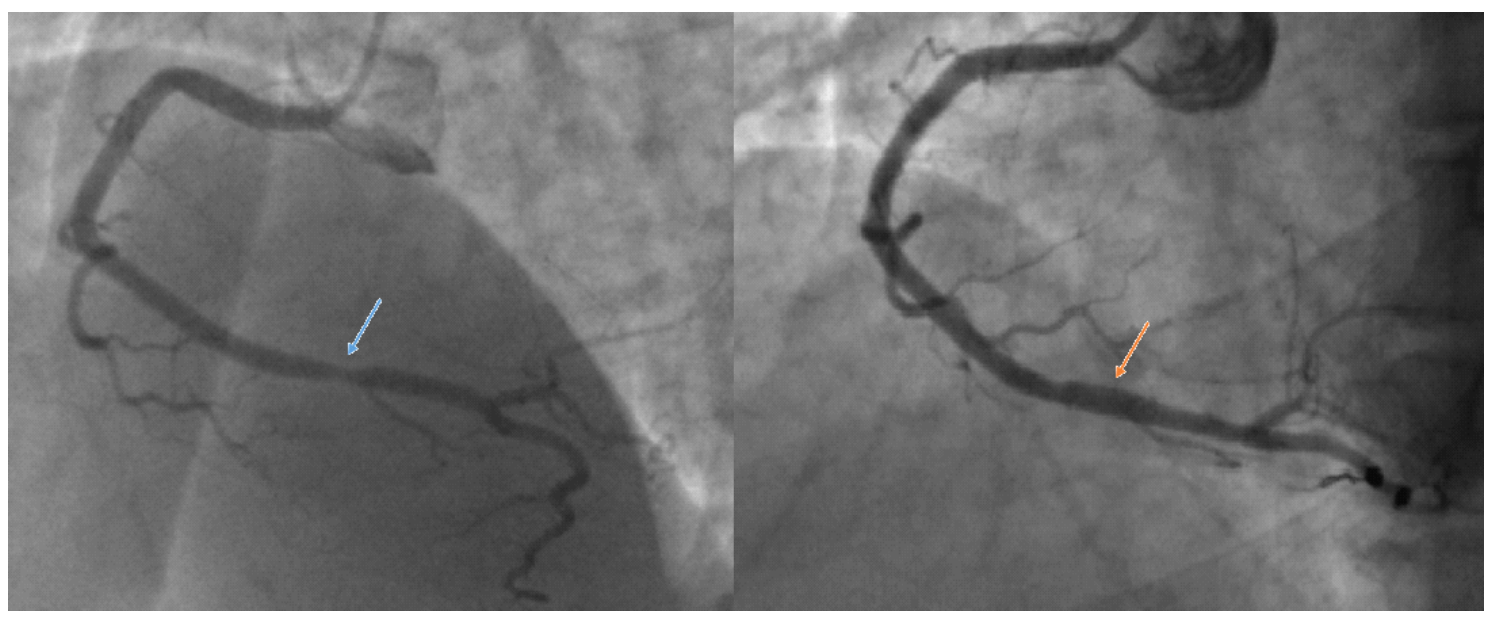

Fig. 2. Coronary angiography showing an intermediate lesion in the distal right coronary artery (left) treated with stent placement (right) 
of plaque instability. The lesion was treated with a drug eluting stent (Figure 2).

Blood analysis was remarkable for a glycated haemoglobin of $5.2 \%$, a C-reactive protein of $10.1 \mathrm{mg} / \mathrm{L}$ $(<5.0 \mathrm{mg} / \mathrm{L})$, a brain natriuretic peptide (BNP) of 122 $\mathrm{pg} / \mathrm{mL}(<100 \mathrm{pg} / \mathrm{mL})$, a total cholesterol of $164 \mathrm{mg} /$ $\mathrm{dL}$, an LDL-cholesterol of $104 \mathrm{mg} / \mathrm{dL}$, an HDLcholesterol of $44 \mathrm{mg} / \mathrm{dL}$, triglicerydes of $100 \mathrm{mg} / \mathrm{dL}$, a peak high-sensitive cardiac troponin I (hs-cTnI) of $5761.2 \mathrm{pg} / \mathrm{mL}(<15.6 \mathrm{pg} / \mathrm{mL})$ and a peak creatinine kinase (CK) of $201 \mathrm{U} / \mathrm{L}$ (29-168 U/L). Imunoglobulline $\mathrm{E}$ and complement fractions were within normal ranges. Tryptase dosing was not performed. Before discharge, the echocardiography revealed good left ventricular function with no regional wall motion abnormalities and the patient was discharged on acetylsalicylic acid, clopidogrel, amlodipin and atorvastatin.

\section{Discussion}

This report illustrates a case of mismanagement due to a series of mishaps - a diagnostic error, a procedural error and a medication error - which resulted in a serious consequence.

The diagnosis initially made was anaphylaxis, on the count of the angioedema and the slight dyspnoea. In fact, skin or mucosal involvement combined with respiratory compromise is reason enough to suspect anaphylaxis [1]. However, anaphylaxis is characterized by a rapid onset, usually within two hours of exposure to an allergen [1], and it is not possible to know in this case how fast the onset was, since the patient was asleep, or if there was an allergen involved, although it is unlikely that the patient could have been exposed during sleep. Nevertheless, in up to $20 \%$ of cases, the allergen will not be identified [1].

Two kinds of acute myocardial infarction associated with anaphylaxis are described, either caused by coronary spasm, plaque erosion/rupture or stent thrombosis: Kounis syndrome which is caused by inflammatory mediators released from mast-cells and platelets [3]; and adrenaline-induced myocardial injury induced by the $\alpha 1$-adrenergic effect causing vasoconstriction or the induction of platelet aggregation [4-13]. Taking into account the typical symptoms and ECG changes occurring shortly after adrenaline injection, coupled with a significant stenosis but with no signs of plaque instability and the rise in troponin, it was assumed that this was a type 2 myocardial infarction (myocardial infarction secondary to an ischaemic imbalance) due to coronary artery spasm [8] caused by adrenaline.

Adrenaline should be administered to all patients with suspected anaphylaxis or with features that could evolve into anaphylaxis. The intramuscular route is preferred because of its rapid onset of action and its better safety profile. The recommended dose is 0.3 $\mathrm{mg}$ to $0.5 \mathrm{mg}$ that can be repeated every 5 to $15 \mathrm{mi}-$ nutes if the response is suboptimal. Intravenous adrenaline administration is only acceptable when there is no response to intramuscular adrenaline and only by strictly titrated infusion guided by close monitoring, since most serious adverse reactions, such as acute myocardial infarction, occur in this setting [1].

It is clear that the dose of $1 \mathrm{mg}$ was excessive and the route of administration was not adequate, and these are probably the main responsible factors for the development of vasospasm. However, cases of serious cardiac events occurring after adrenaline administration are being reported $[6-9,14]$, which emphasize the potential hazards of this treatment. Hence, it could be argued, that adrenaline administration should be withheld unless patients are in a life-threatening condition with clear evidence of cardiovascular or respiratory compromise, since the fatality rate is very low and some milder anaphylactic reactions will resolve spontaneously. Corticoids and anti-histamines can be given in the meantime [15]. This patient complained of mild dyspnoea which was interpreted as a sign of respiratory compromise, but this could have been a rushed assumption, since no wheezing or stridor were present and the patient could have fared well without adrenaline.

Importantly, the lack of skin rash or pruritus, which are highly typical of allergic (histamine-induced) angioedema, associated with the presumably not sudden onset, the inability to identify an allergen and the lack of evidence of an allergic reaction in the blood work, puts the diagnosis of anaphylaxis into question.

ACEI-induced (bradikinin-induced) angioedema is self-limiting, typically involves the face and upper limbs, has a gradual onset and is not associated with rash or pruritus. It is a very rare event in patients taking ACEI, although it accounts for one third of angioedema cases treated in emergency rooms, and is seldom life-threatening. It can develop up to 10 years after initiation of ACEI therapy. It does not require specific treatment, adrenaline, corticosteroids and anti-histamines are ineffective and it resolves after drug discontinuation [2].

Although the diagnosis of both types of angioedema relies on clinical features and no laboratory test can provide undisputable proof, the diagnosis of anaphylaxis can be supported by elevated serum tryptase within a few hours after the start of the symptoms [1], which unfortunately was not performed in this case. Nevertheless, for the reasons described above, it is the authors' opinion that this is a case of ACEI-induced angioedema and not anaphylaxis as initially assumed, which further adds to the wrongful use of adrenaline. 


\section{Conclusion}

Adrenaline is a very useful medication in cases of life-threatening anaphylaxis, but is ineffective in ACEIinduced angioedema. It is very important to distinguish between these two types of angioedema in the emergency department to avoid the wrongful use of adrenaline, which is not without serious adverse events. Since it is difficult to make this distinction, the correct timing, dosage and route of administration of adrenaline are the keys to avoid potential significant side effects.

\section{Conflict of interest}

Nothing to declare

\section{References}

1. Muraro A, Roberts G, Worm M, Bilò MB, Brockow K, Fernández Rivas M, et al, on behalf of the EAACI Food Allergy and Anaphylaxis Guidelines Group. Anaphylaxis: guidelines from the European Academy of Allergy and Clinical Immunology. Allergy 2014; 69: 1026-1045. doi: 10.1111/all.12437

2. Bezalel S, Mahlab-Guri K, Asher I, Werner B, Sthoeger ZM. Angiotensin-converting enzyme inhibitor-induced angioedema. Am J Med 2015; 128: 120-125. doi: 10.1016/j.amjmed.2014. 07.011

3. Kounis NG. Coronary hypersensitivity disorder: the Kounis syndrome. Clin Ther 2013; 35: 563-571. doi: 10.1016/j. clinthera.2013.02.022

4. Tummala K, Maniyal VK, Chandrashekaran R, Mathew N, Ganeshwala G. Cardiac anaphylaxis: a case of acute ST-segment elevation myocardial infarction after IM epinephrine for anaphylactic shock. Am J Emerg Med 2013; 31: 1157.e1-3. doi: 10.1016/j.ajem.2013.03.025

5. Cunnington C, McDonald JE, Singh RK. Epinephrine-induced myocardial infarction in severe anaphylaxis: is nonselective $\beta$ - blockade a contributory factor? Am J Emerg Med 2013; 31 : 759.e1-2. doi: 10.1016/j.ajem.2012.11.022

6. Shaver KJ, Adams C, Weiss SJ. Acute myocardial infarction after administration of low-dose intravenous epinephrine for anaphylaxis. CJEM 2006; 8: 289-294. doi: 10.1017/ S1481803500013890

7. Rubio Caballero JA, Oteo Domínguez JF, Maicas Bellido C, Cantón T, Barciela R, García Moreno LM, et al. An adrenalineinduced vasospasm as the form of presentation of variant angina. Rev Esp Cardiol 1999; 52: 273-276

8. Saff R, Nahhas A, Fink JN. Myocardial infarction induced by coronary vasospasm after self-administration of epinephrine. Ann Allergy 1993; 70: 396-398

9. Ferry DR, Henry RL, Kern MJ. Epinephrine-induced myocardial infarction in a patient with angiographically normal coronary arteries. Am Heart J 1986; 111: 1193-1195

10. Park JS, Min JH, Kang JH, In YN. Acute Myocardial Infarction Due to Stent Thrombosis after Administration of Intravenous Epinephrine for Anaphylaxis. Chin Med J (Engl) 2015; 128 : 2692-2693. doi: 10.4103/0366-6999.166020

11. Jackson CE, Dalzell JR, Hogg KJ. Epinephrine treatment of anaphylaxis: an extraordinary case of very late acute stent thrombosis. Circ Cardiovasc Interv 2009; 2: 79-81. doi: 10.1161/ CIRCINTERVENTIONS.108.820266

12. Kasim S, AbuBakar R, McFadden E. Anaphylaxis from wasp stings inducing coronary thrombus. Case Rep Cardiol 2012; 2012: 701753. doi: 10.1155/2012/701753

13. Brener ZZ, Zhuravenko I, Bergman M. Acute myocardial injury following penicillin-associated anaphylactic reaction in a patient with normal coronary arteries. Am J Med Sci 2007; 334: $305-$ 307. doi: 10.1097/MAJ.0b013e3180a6ee10

14. Madias J. Epinephrine administration and Takotsubo syndrome: Lessons from past experiences. Int J Cardiol 2016; 207: 100102. doi: 10.1016/j.ijcard.2016.01.145

15. Cervellin G, Sanchis-Gomar F, Lippi G. Adrenaline in anaphylaxis treatment. Balancing benefits and harms. Expert Opin Drug Saf 2016; 15: 741-746. doi: 10.1517/14740338.2016.1167870 